\title{
Wide-bandgap Power Semiconductors for Electric Vehicle Systems: Challenges and Trends
}

\author{
Thang V. Do, University of Sherbrooke, Canada \\ João P. Trovão, University of Sherbrooke, Canada \\ Ke Li, Coventry University, UK \\ Loic Boulon, Univ. du Québec à Trois-Rivières, Canada
}

In recent years, researchers have been attracted towards the application of Wide-Bandgap (WBG) power semiconductor devices such as Silicon Carbide (SiC) and Gallium Nitride $(G a N)$ in Electric Vehicle (EV) applications. Their advantages over Silicon (Si) power semiconductors are lower power losses, higher switching frequencies and higher junction temperatures. Thus, the usage of WBG power semiconductor devices for EV power electronic systems is to improve EV efficiency, reliability, and mileage. However, these adoptions are still under challenges in terms of packaging and power converters design. In this paper, future trends and prospects of using $W B G$ power semiconductor devices in EV systems are first presented. Then, recent progress of different commercial WBG power semiconductor devices are reviewed and different solutions in order to solve the research and development challenges are evaluated.

\section{Trends of WBG semiconductors for EV systems and Wide-Bandgap devices progress}

Power electronics systems play an important role to resolve the challenges the electrical vehicle (EV) industry is facing today, such as efficiency, mileage, and cost, as it determines the EV energy management in an efficient and reliable way. With rapid development of semiconductor technologies, Wide-Bandgap (WBG) power semiconductor devices based on Silicon Carbide (SiC) and Gallium Nitride $(\mathrm{GaN})$ have been recognized as the next-generation power semiconductor devices. Comparisons of using WBG and Si power semiconductor devices in different parts of EV systems with the prototype are illustrated in Figure 1 For motor drive applications, while efficiency and power density are improved by $1.4-4.4 \%$ and $206-334 \%$ respectively, the total mass is significantly reduced by $46 \%$, compared to Si-based EV systems. For on-board converter, the efficiency and power density are increased by $0.5-3.75 \%$ and $266-976 \%$ respectively, the system size and volume are notably decreased. For charger, all these parameters are also significantly improved when compared with systems using Silicon [1].

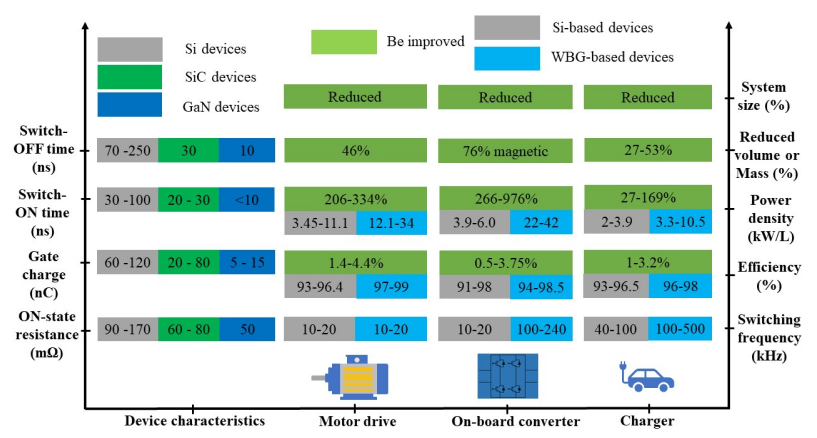

Figure 1 Comparison of WBG and Si devices in EV systems.

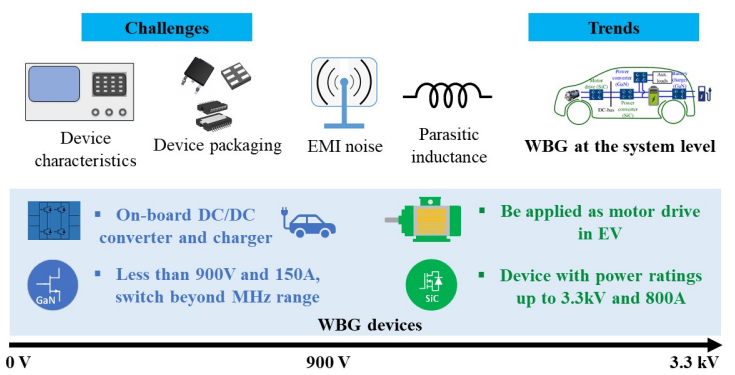

Figure 2 Challenges and trends of using WBG for EVs.

Many benefits have been gained from each part of the EV systems by adopting WBG power semiconductors. These results bring a trend towards using WBG in system-level converters to not only decrease the system size and volume but also increase power, performance for all future EV systems in Figure 2. Nowadays, Tesla was the first EV automaker to employ a full $\mathrm{SiC}$ power module in the main inverter for the Tesla Model 3. In 2015, Toyota utilized SiC devices such as transistors and diodes in the inverter and the internal dc-dc converter of the power control unit for the Camry hybrid prototype to test on-road. In May 2019, an All GaN Vehicle buggy using a GaN inverter, jointly researched by Nagoya University, Future Materials and Systems Research Institute, and Toyota Advanced Power Electronics, has successfully conducted an on-road test at the Fuji Speedway. Along with 
that, increasing the voltage and current ratings for GaN devices and developing integrated $\mathrm{GaN}$ power semiconductor ICs are important research areas for EV applications. Besides, new types of passive components that utilize new magnetic materials as amorphous Co-Zr-Ta alloys integrate with magnetic thin-film inductors have high relative permeability $\left(\mu_{\mathrm{r}}>500\right)$ and low coercivity $\left(\mathrm{H}_{\mathrm{C}}<1 \mathrm{Oe}\right)$, which can operate at a higher frequency, higher temperatures and higher flux density with low losses. Therefore, they are particularly necessary to be used with WBG devices at the system level in the future. But, to use these WBG devices effectively, new challenges are needed to pay attention to decrease EMI noise level, suitable gate drivers design as well as PCB layout for the EV-based power converters with high frequencies up to MHz. Recently, many research areas have been studied to solve these issues such as different approaches to characterize SiC devices under various operating conditions [2], [3] and to understand the effect of current collapse on GaN devices [4]. Minimizing $\mathrm{L}_{\text {para }}$ value for $\mathrm{GaN}$ devices is presented in [5]. Moreover, the packaging of the SiC power module by using new materials and cooling structures is presented in [6], [7], respectively. Comparison of using WBG devices for dc-dc converters is implemented in [8].

Moreover, the advantages of using WBG devices over Sidevices in EV systems can be explained through their device characteristics. Characteristics comparison of $650 \mathrm{~V} / 30 \mathrm{~A}$ devices with different technologies are given in Figure 1 where it can be found both $\mathrm{SiC}$ and $\mathrm{GaN}$ devices are able to decrease the device $\mathrm{ON}$-state resistance, required gate charge and switching time by almost one order of magnitude, resulting in less power losses and higher switching frequency $\left(\mathrm{F}_{\mathrm{sw}}\right)$ than silicon ( $\mathrm{Si}$ ) counterpart. In addition, both $\mathrm{SiC}$ and $\mathrm{GaN}$ semiconductor die can operate above $600^{\circ} \mathrm{C}$, which is higher than $\mathrm{Si}$ (limited to $150-175^{\circ} \mathrm{C}$ ), which satisfies the application for hybrid electric vehicles to use only one internal combustion engine cooling $\left(105^{\circ} \mathrm{C}\right)$ and for battery electric vehicles as integrated motor drive. Those benefits are drawing huge research interest to revolutionize power electronics technologies towards higher efficiency and higher power density, which will bring huge impact for EV industry by increasing efficiency, mileage, reliability and by reducing overall system weight and cost.

We see a rapid development of commercial WBG devices. As illustrated in Figure 3. we can find both SiC single devices (diodes, transistors) and power modules with power ratings above $1.2 \mathrm{kV} / 100 \mathrm{~A}$ in the market, which makes them a strong competitor to $\mathrm{Si}$ for the application as $\mathrm{EV}$ motor drive and high-power converter (battery to high voltage DC link). For $\mathrm{GaN}$ devices, as the majority of them are standalone devices with power rating inferior to $650 \mathrm{~V} / 100 \mathrm{~A}$ (GaNSystem just released a $650 \mathrm{~V} / 300 \mathrm{~A}$ GaN module when we prepare this paper). However, they can switch towards megahertz range (one or two orders of magnitude higher than $\mathrm{Si}$ ), which reduces required passive devices (inductor and capacitor) size used in power electronics converters, and they can be applied in EV on-board chargers and low power converters (battery to auxiliary power).

\section{SiC power semiconductor devices}

It is summarized in Table 1 commercial SiC device types, modules, and their power ratings. Those devices are accessible with vertical structure.

- Diode: Schottky diodes and Merged PiN Schottky (MPS) diodes are considered as the two primary types of the SiC diodes. With power ratings above $1.2 \mathrm{kV} / 50 \mathrm{~A}$, both can be applied in EV on-board converters.

- Transistors: Unipolar devices such as JFET and MOSFET are the most popular commercial components. For $\mathrm{SiC}$ JFET, most of the available components are in depletion mode (Normally-ON devices with a threshold voltage less than zero, $\left.\mathrm{V}_{\mathrm{th}}<0\right)$. Enhancement power transistors (Normally-off, $\mathrm{V}_{\mathrm{th}}>0$ ) are preferred in power electronics converters for safety reason in case of device gate driver fault. Normally-ON SiC-JFET with low voltage $\mathrm{Si}$ MOSFET in Cascode structure is one solution, where SiMOSFET is controlled by a gate driver. For SiC MOSFET, the commercial components are in enhancement mode. With a power rating up to $1.7 \mathrm{kV} / 120 \mathrm{~A}$, they can meet the needs of most applications in EV based DC-DC converters as well as multi-phase motor drive [1].

- Power module: Along with SiC single devices, SiC power modules are commercially available from various manufactures (Semikron, Hitachi, Infineon, ROHM and Wolfspeed etc.) for high current applications up to 800A, which meets the peak current requirement in EV motor drive. However, the transition from single devices to power modules still has challenges such as the balance of each current loop for equally sharing current and heterogeneous integration of device chips, substrate, and housing to reduce $\mathrm{L}_{\text {para }}$, temperature stress, and increase the packaging reliability.

For single device packaging, besides conventional TO-247 packaging where there are three pins for drain, gate and source, there is an additional source pin for gate driver connection to

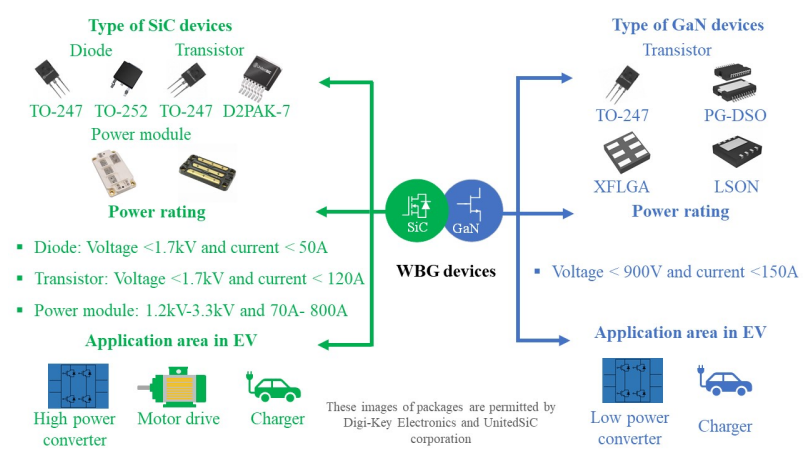

Figure 3 Progress of SiC and GaN devices in the market. 
minimize Lpara of gate driver loop in some commercial packaging. It can also be noted that in power module solution, besides single-phase and three-phase power modules, there is a three-level power module available, which offers extra degree of freedom for electrical machine control.

\section{GaN power semiconductor devices}

It is summarized in Table 1 commercial GaN device types and their power ratings. Those devices are available in lateral structure. There are three types of GaN transistors: highelectron-mobility-transistors (HEMT), cascode transistor and gate-injection-transistor (GIT). For $650 \mathrm{~V}$ GaN transistors, devices current ratings vary from 3.6A (TP65H480G4JSG) to 200A (V08TC65S2A), which covers a wide application range from $1 \mathrm{~kW}$ to $70 \mathrm{~kW}$. GaN-HEMTs are easily fabricated as normally-on devices due to natural presence of the electron in the channel. To be more suitable for power electronics converters, most commercial GaN-HEMT is available in enhancement mode, either by designing different device

Table $1 \mathrm{SiC}$ and GaN power semiconductor devices and power module of different manufactures

\begin{tabular}{|c|c|c|c|}
\hline \multicolumn{4}{|c|}{ SiC power switching device } \\
\hline Manufacturer & Device & Power module & $\begin{array}{l}\text { Maximal power } \\
\text { rating }\end{array}$ \\
\hline Littlefuse, ST & MOSFET & & $1.2-1.7 \mathrm{kV} / 25-120 \mathrm{~A}$ \\
\hline GeneSiC & $\begin{array}{l}\text { Schottky } \\
\text { diode, BJT, } \\
\text { MOSFET, } \\
\text { PiN diode }\end{array}$ & & $\begin{array}{l}\text { - } \text { Schottky diode: } \\
\text { 1.7-3.3kV/200-5A } \\
\text { - } \mathrm{MOSFET:} \mathrm{1.2-} \\
3.3 \mathrm{kV} / 60-5 \mathrm{~A} \\
\text { - } \mathrm{BJT}: 1,2- \\
1.7 \mathrm{kV} / 100-15 \mathrm{~A} \\
\text { - } \mathrm{PiN} \text { diode: 8- } \\
15 \mathrm{kV} / 2-1 \mathrm{~A}\end{array}$ \\
\hline $\begin{array}{l}\text { Semikron, } \\
\text { Hitachi }\end{array}$ & & $\begin{array}{l}\text { Single phase - } \\
\text { Three phase }\end{array}$ & $\begin{array}{l}1.2 \mathrm{kV}-3.3 \mathrm{kV} / 540- \\
800 \mathrm{~A}\end{array}$ \\
\hline $\begin{array}{l}\text { Microsemi, } \\
\text { Infineon, } \\
\text { ROHM, } \\
\text { Wolfspeed }\end{array}$ & $\begin{array}{l}\text { Diode, } \\
\text { MOSFET }\end{array}$ & $\begin{array}{l}\begin{array}{c}\text { Full diode } \\
\text { bridge }\end{array} \\
\text { - Single phase } \\
\text { - Three } \\
\text { phase } \\
\text { - Three } \\
\text { level }\end{array}$ & $\begin{array}{l}\text { - } \text { Diode: } 1.2- \\
1.7 \mathrm{kV} / 50 \mathrm{~A} \\
\text { - } \\
\text { MOSFET: 1.2- } \\
1.7 \mathrm{kV} / 125-70 \mathrm{~A} \\
\text { - Module: } 1.2- \\
1.7 \mathrm{kV} / 580- \\
225 \mathrm{~A}\end{array}$ \\
\hline \multicolumn{4}{|c|}{ GaN power switching device } \\
\hline Manufacturer & Device type & Packaging & $\begin{array}{c}\text { Maximal power } \\
\text { rating }\end{array}$ \\
\hline $\begin{array}{l}\text { Transphorm, } \\
\text { Nexperia }\end{array}$ & Cascode & TO247, PQFN & $650-900 \mathrm{~V} / 80-15 \mathrm{~A}$ \\
\hline $\begin{array}{c}\text { EPC, } \\
\text { GaNSystems, } \\
\text { Exagan }\end{array}$ & HEMT & $\begin{array}{c}\text { TO247, PQFN, } \\
\text { Bare die, } \\
\text { GaNPX }\end{array}$ & $100-650 \mathrm{~V} / 90-150 \mathrm{~A}$ \\
\hline $\begin{array}{l}\text { Panasonic, } \\
\text { Infineon }\end{array}$ & GIT & $\begin{array}{c}\text { DFN, DSO, } \\
\text { HSOF, LSON }\end{array}$ & $400-650 \mathrm{~V} / 30 \mathrm{~A}$ \\
\hline $\begin{array}{l}\text { TI, ViSiC, } \\
\text { Navitas }\end{array}$ & $\begin{array}{c}\text { Integrated } \\
\text { with gate } \\
\text { driver or } \\
\text { normally-off } \\
\text { device }\end{array}$ & QFN & $600 \mathrm{~V} / 12 \mathrm{~A}-200 \mathrm{~A}$ \\
\hline
\end{tabular}

structures (recessed gate or p-type gate) or by combining an enhancement low voltage Si-MOSFET in cascade structure and normally-off transistors to ensure safety operation.

Both of GaN-HEMT and cascade transistors are voltagecontrolled device and drain-source current is in bi-directional flow, which operates similarly to MOSFET. A different type of a normally-off GaN transistor is GIT which is a current controlled device. With voltage and current up to $900 \mathrm{~V}, 150 \mathrm{~A}$ respectively, GaN transistors are more suitable to be employed as battery charger and low power converter for EV [1].

It can be noted that mainly single device is available currently in the market. Regarding device packaging, most commercial devices are with SMD type. One advantage of that is to reduce $\mathrm{L}_{\text {para }}$ value of interconnection. Some manufacturer offers GaN device with integrated gate driver to further reduce $\mathrm{L}_{\text {para }}$ of gate driver loop.

\section{Challenges of adopting WBG power semiconductor devices for EV systems}

Although using WBG power semiconductor devices have different benefits, challenges are well presented due to their fast-switching transition. Understanding device characteristics, optimizing interconnection parasitic, increasing packaging reliability, and minimizing electromagnetic interference (EMI) noise are necessary for better application of WBG devices in $\mathrm{EV}$ power electronic systems. In the following subsections, various measures to solve these research and development challenges for using $\mathrm{SiC}$ and $\mathrm{GaN}$ devices in $\mathrm{EV}$ systems will be discussed.

\section{Challenges and solutions of SiC power semiconductor devices}

\section{Device characterization}

Gaining knowledge of fast switching transition of $\mathrm{SiC}$ transistors plays an important role in their adoption into EV power electronics systems, because it influences the device power losses and EMI noise level. Different solutions are proposed to characterize the device under various operation conditions in Figure 4 and Figure 5:

- Non-linear inter-electrode capacitance [2].

- Switching transition and losses under both hard switching and soft switching conditions [2], [3].

- Device capacitance losses.

A characterization method using multiple current probes to measure power transistors inter-electrode capacitances is presented in Figure 5. In this method, device and measurement equipment are isolated by the current probes. An AC smallsignal current is injected into the measuring circuit via the current injection probe (CIP) by the vector network analyzer (VNA). Then, this current is measured by the current receiving probe (CRP) after crossing over an unknown impedance that can be attained based on the form of scattering (S)-parameter. 
By varying device operation conditions (biased under different $\mathrm{V}_{\mathrm{gs}}, \mathrm{V}_{\mathrm{ds}}$ voltages or in linear region) its non-linear interelectrode capacitance can be obtained. Device inter-electrode capacitances can also be measured by using an impedance analyzer (IA), and an external DC voltage source [2]. By having values of inter-electrode capacitances, power transistor switching losses and time can be estimated.

A comparison of the switching transients and losses of 1200V SiC-MOSFET, 900V SiC-MOSFET and 600V SiCMOSFET with the same current rating is presented in [2], [3]. Because of low electron mobility $\left(400-900 \mathrm{~cm}^{2} / \mathrm{V} . \mathrm{s}\right), 600 \mathrm{~V} \mathrm{SiC}-$ MOSFET has higher figure of merit (Ron.Q) than $900 \mathrm{~V}$ and $1200 \mathrm{~V}$ counterpart. This has been further confirmed in above papers that both $1200 \mathrm{~V}$ and $900 \mathrm{~V}$ SiC-MOSFET have smaller ON-state resistance and smaller inter-electrode capacitance than $600 \mathrm{~V}$ device, resulting in shorter switching transients and lower power losses under different switching conditions. It is also presented that soft switching is an effective technique to reduce device switching losses.

To estimate SiC-MOSFET soft switching losses due to charge and discharge of device output capacitance Coss, a new circuit model including an effective Coss in serial connection with a series frequency-dependent resistance is employed. The required model parameters can be extracted from datasheet and by using an impedance analyzer. Therefore, the approach presented the dependence of device capacitance losses on frequency, voltage, as well as $\mathrm{dV} / \mathrm{dt}$ values and precisely anticipated its Coss related losses at a wide range of $F_{\text {sw. }}$.

2 Parasitic inductances

The $\mathrm{L}_{\text {para }}$ of power electronics converters have a major effect on converter performance, including power losses, voltage overshoot and reliability.
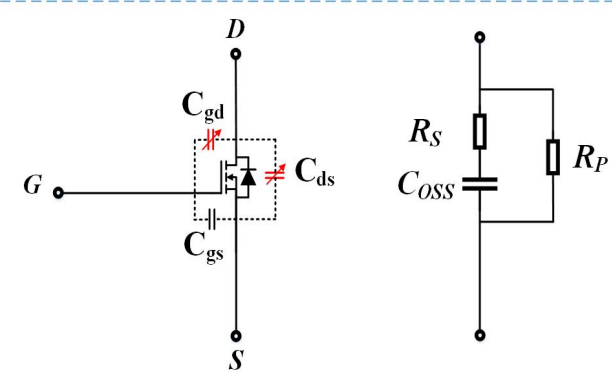

Non-linear inter-electrode Device capacitance losses capacitance

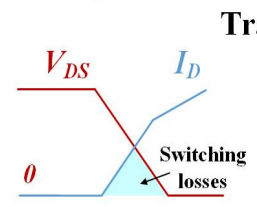

Transition

Hard switching conditions

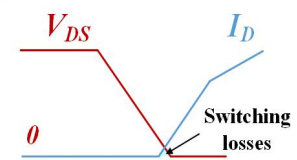

Soft switching conditions

Figure 4 Characterizing device of SIC MOSFET under various operating conditions.

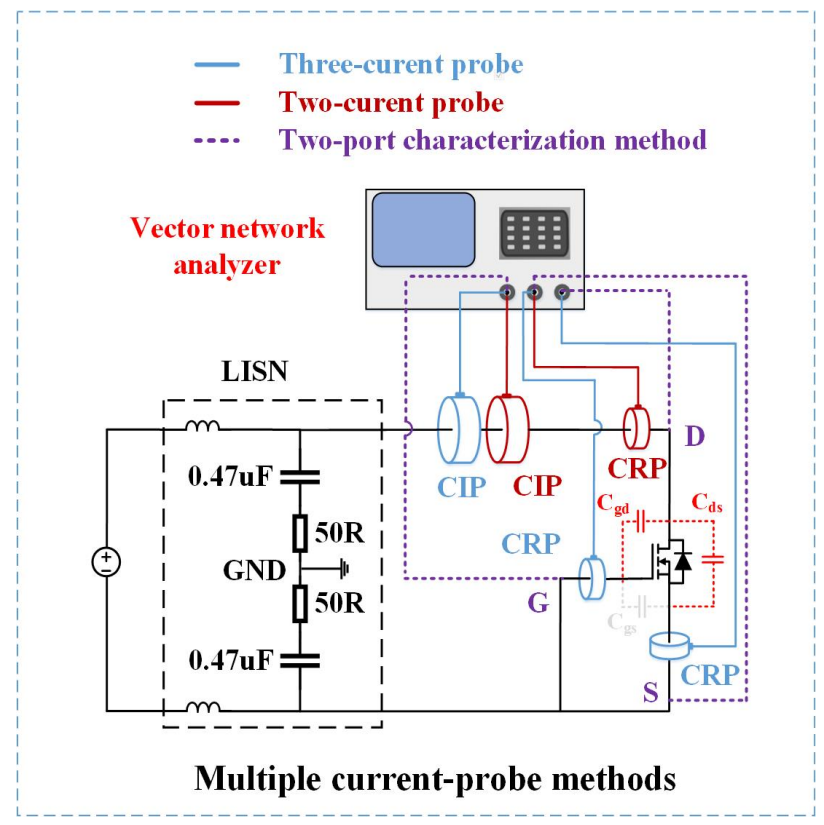

Figure 5 Multiple current-probe methods and two-port characterization method.

There are various measures to characterize and reduce $\mathrm{L}_{\mathrm{para}}$ value due to interconnection and layout such as:

- Two-port characterization method for obtaining parasitic inductances.

- Using low-inductance sectional busbar.

Two-port S-parameters measurement can be used to measure $\mathrm{L}_{\text {para }}$ of $\mathrm{SiC}$ MOSFETs for single device and power modules. By modeling a SiC MOSFET as a two-port network, the S-parameters are first determined and then transformed into impedance (Z)-parameters from network analyzer measurement. After network analysis steps of these Zparameters, the values of the $\mathrm{L}_{\text {para }}$ are given more correctly than a single-port impedance measurement method which is usually utilized.

A laminated busbar is typically applied today in EV traction inverters. This type of busbar utilizes parallel copper sheets to build a low inductance connection from dc-link capacitors to all power switching devices. Unlike the laminated busbars, a low-inductance dc busbar of finger-crossed shape for the application of SiC-based traction inverters utilized capacitor sections mounted on the up of each $\mathrm{SiC}$ power module. Therefore, the $\mathrm{L}_{\text {para }}$ value of switching loop is decreased from approximately $25 \mathrm{nH}$ to approximately $13.1 \mathrm{nH}$ by canceling finger-shaped contacts connecting between the busbar plates and the modules in the laminated busbars. Moreover, as $\mathrm{L}_{\text {para }}$ is reduced, it is not necessary to use snubber circuit, which is commonly used to reduce the impact of Lpara on device switching. 
3 The packaging of $\mathrm{SiC}$ power modules

Low-temperature stress and high fault tolerance of $\mathrm{SiC}$ power modules are critical to apply immediately in hybrid EV which can operate with a single cooling loop (temperature $>$ $105^{\circ} \mathrm{C}$ ). To lower down temperature stress and improve reliability for fault tolerance of modules, it is necessary to use new materials and cooling structures to reduce overall thermal resistance $\left(\mathrm{R}_{\mathrm{th}}\right)$, such as: using thick $\mathrm{Cu}$ heat spreader [6], double-sided direct-cooling technology [7]. To improve reliability for fault tolerance, it is necessary to lower down device $\mathrm{ON}$-state resistance and switching loop $\mathrm{L}_{\text {para }}$ of the packaging [9].

Authors in [6] investigated direct-cooled power module technologies to meet the need of lower $R_{\text {th }}$ and stress relaxation. By placing a thick Copper $(\mathrm{Cu})$ heat spreader under the $\mathrm{SiC}$ chip for lower $\mathrm{R}_{\text {th }}$ and using a thin closed Aluminum water jacket for the relaxation of stress, $\mathrm{R}_{\mathrm{th}}$ is reduced by $34 \%$ from $1.515 \mathrm{~K} / \mathrm{W}$ to $1 \mathrm{~K} / \mathrm{W}$, compared with common directcooled power modules.

To decrease further the percentage of the $\mathrm{R}_{\mathrm{th}}$, by using the double-sided direct-cooling technology, heat radiation can go through both the top and bottom of SiC MOSFET when compared to the common direct-cooled power modules which the heat radiation just goes through the bottom side of the chip in [7]. Therefore, the $\mathrm{R}_{\text {th }}$ was decreased by $35 \%$ from $0.262 \mathrm{~K} / \mathrm{W}$ to $0.17 \mathrm{~K} / \mathrm{W}$, compared to the common single-sided direct cooling.

A power module with ultra-low on-resistance $(7 \mathrm{mOhm})$ $\mathrm{SiC}$ JFET $650 \mathrm{~V} / 100 \mathrm{~A}$ in cascode structure and built-in ceramic decoupling capacitor is proposed in [9]. In short-circuit test, the device can withstand $8 \mu$ s short-circuit duration, peak current up to $400 \mathrm{~A}$ and temperature up to $200^{\circ} \mathrm{C}$, which meets the requirement for $\mathrm{EV}$ inverter drive.

To resolve the challenge on reliability, different materials with matched coefficient of thermal expansion (CTE) as WBG devices are used. This includes a wide range of ceramic materials $\left(\mathrm{Al}_{2} \mathrm{O}_{3}, \mathrm{AlN}, \mathrm{BeO}\right.$, and $\left.\mathrm{Si}_{3} \mathrm{~N}_{4}\right)$ for substrate, metal matrix composite with $\mathrm{Mo}-\mathrm{Cu}$ for conductor, die attach based on high temperature soldering material (Au-Ge, Au-Sn), silver sintering and transient liquid phase bonding technique. Those improvements can be further measured by the numbers of thermal cycles and power cycles withstand. For example, it is found that no delamination or cracking was observed after 1000 thermal cycles $\left(-55\right.$ to $\left.200^{\circ} \mathrm{C}\right)$ by using $\mathrm{Al}_{2} \mathrm{O}_{3}-\mathrm{MoCu}$ structure. The $\mathrm{R}_{\text {th }}$ of $\mathrm{Ag}$ joints is stable after 116,000 power cycles $\left(50\right.$ to $\left.175^{\circ} \mathrm{C}\right)$. By contrast, $\mathrm{R}_{\text {th }}$ of $\mathrm{Pb}_{5} \mathrm{Sn}$ rapidly increases 10 times after 52,000 cycles [10].

Regarding $\mathrm{SiC}$ device reliability, high current avalanche robustness is important for safe operation. It is presented by Bai et al. in [11] a TCAD thermoelectric simulation to further understand how hot spots formed in failed devices. Nevertheless, technical data from Wolfspeed show that devices successfully pass 1000 hours of high temperature gate bias and reverse bias. Field return data also show that there is less than 5 fails per billion device hours for over 2 trillion device field hours, which confirms the reliability continues to be improved. Moreover, understanding the terrestrial neutron single-event burnout (SEB) failure rates for $\mathrm{SiC}$ devices is necessary for operation under high-blocking voltage. F. Principato et al. in [12] presented accelerated tests using ultra-fast neutrons, which leads to the SEB for $\mathrm{SiC}$ and $\mathrm{Si}$ devices. It is found that $\mathrm{SiC}$ devices showed notably lower failure in time than Si devices.

\section{Mitigate the EMI noise}

Fast switching transition of $\mathrm{SiC}$ transistors causes an increase in the electromagnetic interference (EMI) noise for the EV power converter in terms of an overshoot of transistor switching voltage and increased conducted and radiated EMI noise level. A conventional approach to reduce EMI noise is to lower down transistor switching transients, but at the cost of higher switching losses. It is important to find approaches to not only decrease the noise but also retain benefits of $\mathrm{SiC}$ fast switching such as:

- Multistage RC gate driver circuit to effectively control high speed $\mathrm{dV} / \mathrm{dt}$.

- New housing structure to lower down radiated EMI level.

By using the multistage $\mathrm{RC}$ gate driver circuit with different gate resistance and capacitance values of the RC circuits, the high-speed $\mathrm{dV} / \mathrm{dt}$ can be controlled more effectively, when compared to the conventional gate driver which is controlled by a single constant resistor. Thus, surge voltage and current in transition can be reduced in comparison with a standard gate driver.

In order to mitigate the radiation noise level from the SiCbased EV traction inverter housing, inverter housing dimensions and a grounding approach were investigated in. By lowering the housing height and increasing the housing area, the ground capacitance from the housing to the body ground is increased. Therefore, the antenna length and impedance can be decreased resulting in mitigating the radiation noise level.

5 Losses of $\mathrm{SiC}$ devices under different $\mathrm{EV}$ road conditions

It is important to consider EV driving conditions to understand the benefit of $\mathrm{SiC}$ devices for EV on system scale. A comparison of efficiencies and losses via EPA standard driving cycles, including the UDDS, HWFET, and US06 between the $1200 \mathrm{~V} \mathrm{SiC}-$ based and $600 \mathrm{~V}$ and $1200 \mathrm{~V}$ Si-based traction inverter is investigated in [13]. Therefore, using a $1200 \mathrm{~V} \mathrm{SiC}$-based traction inverter results in decreasing the peak losses and average urban driving losses by a maximum factor of four, a maximum factor of three respectively, compared to the $600 \mathrm{~V}$ and $1200 \mathrm{~V}$ Si-based traction inverters. Thus, the EV SiC-based cooling system size and volume may be reduced, which suggests an improvement on EV range. Furthermore, peak power losses are seen in the peak torque region, while efficiency showed in proportional increase with power. The traction inverter gains the highest average efficiency for the HWFET driving cycle but the lowest average 
efficiency for the UDDS driving cycle. This is because the efficiency characteristic of the traction inverter is low at low RPM regions and high at the regions of high RPM with high torque.

\section{Challenges and solutions of GaN power semiconductor devices}

1 Effect of current collapse and characterization methods

Understanding the device reliability of $\mathrm{GaN}$ power transistors is crucial to widely apply them for EV based power electronics systems. Nevertheless, because of the trapped charge in device structure, $\mathrm{GaN}$ transistors suffer from current collapse, which results in shifted device static characteristics after gate, drain voltage and current bias. The trapped charges are strongly dependent on device operation conditions (voltage, current, temperature, duty cycle, $\mathrm{F}_{\mathrm{sw}}$ etc.) Therefore, new characterization methods are necessary to study its impact on power losses of EV based power converter.

Authors in [4] proposed a measurement circuit based on a full bridge circuit to characterize dynamic ON-state resistance $\mathrm{Rds}(\mathrm{on})$ for GaN power semiconductor transistors in highfrequency converters in Figure 6. By using trapezoidal current mode, the measurement error due to $\mathrm{L}_{\text {para }}$ can be eliminated, therefore $\operatorname{Rds}(\mathrm{on})$ value can be precisely determined. Thus, device dynamic value can increase $60 \%$ than its static value while switching at $1 \mathrm{MHz}$, which further increases device conduction losses.

Moreover, a revised device double pulse test fixture to study the impact of current collapse on device switching losses is also proposed in this reference. As device voltage bias time cannot be accurately controlled in conventional double test circuit based on one half-bridge leg, an additional half-bridge leg is added to compare device switching transients under biased and unbiased conditions. It is shown that current collapse may increase $20 \%$ switching losses, which is due to device shifted static characteristics after bias.

\section{Optimizing GaN power converter design}

Under GaN device fast switching transients (with orders around $\mathrm{A} / \mathrm{ns}$ and $10-100 \mathrm{~V} / \mathrm{ns}$ ), power loop and gate loop $\mathrm{L}_{\text {para }}$ values should be minimized to few nano-Henry or even smaller to avoid overshoot and sustained oscillations, which deteriorates GaN power converter stability. Therefore, reducing $\mathrm{L}_{\mathrm{para}}$ value is necessary to increase the stability and operation range of the GaN-based high-frequency power converter. Heterogenous integration using both hybrid PCB and direct bond copper (DBC) is one solution to retain low power loop $(\sim 2 \mathrm{nH})$ and low gate loop $(0.3-0.8 \mathrm{nH}) \mathrm{L}_{\text {para }}$ values [5].

Reducing EMI noise level such as common-mode current noise level of GaN-based power converter is crucial to maximize the benefits of $\mathrm{GaN}$ transistor fast switching. One approach is to decrease the parasitic capacitance in layout design of GaN-based power converter by reducing the area between switching node and ground plane in Figure 7

Operating EV-based power electronics converters with a high $\mathrm{F}_{\mathrm{sw}}$ has a major influence on increasing magnetic losses, including core and winding losses due to skin and proximity effects. There are different approaches to reduce it by: using magnetic with variable width winding structure [14] and using magnetic integration method [15].

To decrease the winding loss, planar magnetics with variable width winding structure are investigated in [14]. The total winding resistance is minimized by regulating the inner and outer track width to attain an optimal structure. Therefore, the proposed single-switch converter showed higher efficiency of approximately $2.7 \%$ over the one utilizing the non-variable structure.

Authors in [15] studied the magnetic integration approach to solve problems of multiple cores for $1 \mathrm{MHz}$ LLC converterbased $\mathrm{GaN}$ devices. The core loss is reduced by integrating four transformers and using a four-layer PCB as the windings to employ flux cancellation and decrease flux density in the magnetic plates. This converter gained $97.6 \%$ and $54.9 \mathrm{~kW} / \mathrm{L}$ for the peak efficiency and the power density at $800 \mathrm{~W}$, respectively.

\section{High-power applications}

To solve the challenges of high-power application, it is necessary to put several devices/modules in parallel, where it is particularly important to minimize the impact of mismatch of parasitic elements on device switching transients (current sharing). There are different approaches to minimize $\mathrm{L}_{\text {para }}$ influences such as: Passive compensation solutions using coupled power-source inductors and drive-source resistors.

Active control gate, where unbalanced currents are measured by using differential current transformers across the $\mathrm{L}_{\mathrm{para}}$ and removed by changing the delay time of gate signals. And, optimal direct bonded copper (DBC) layout by dividing the output DBC layout with split DBC patterns. As pointed out, the unbalance currents are decreased from $15 \%$ to $3 \%$ by using passive-compensation method presented in [16]. 


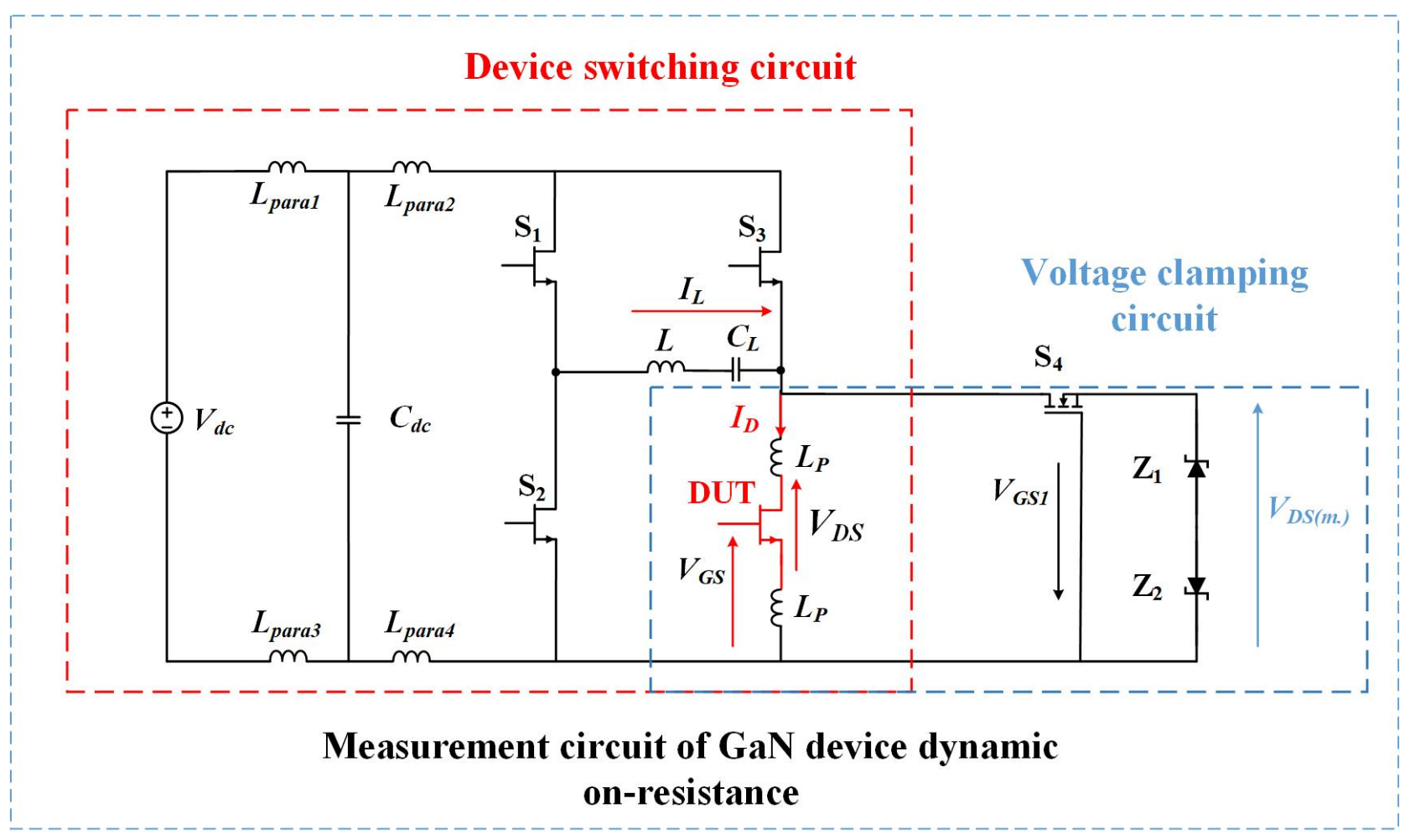

Figure 6 Device static characteristics and measurement circuits of the effect of current collapse on GaN device (based on [4]).

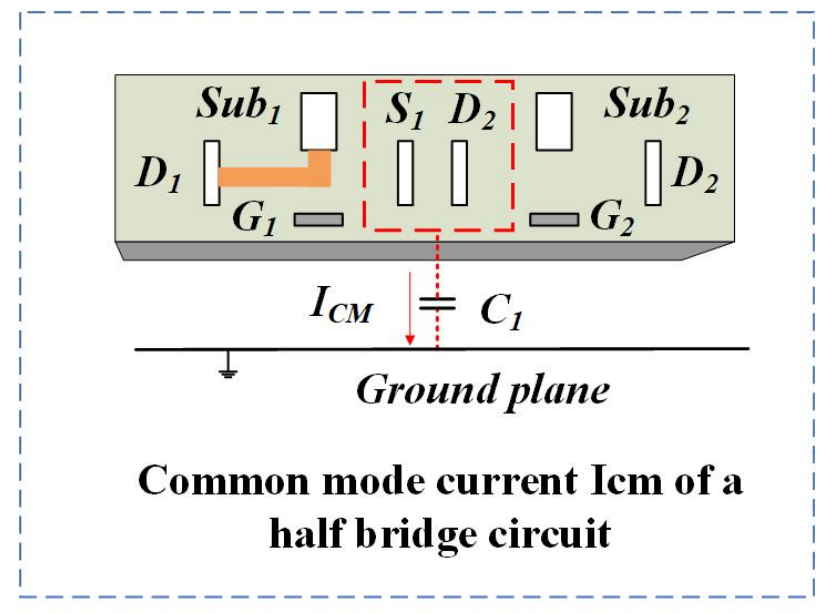

Figure 7 Common mode current of a half bridge circuit.

\section{Discussion and Conclusion}

This paper reviewed the recent progress of WBG power semiconductor devices in the market and trends, and challenges of the adoption of WBG devices for EV systems. For the future, increasing power ratings of $\mathrm{GaN}$ devices and using new magnetic materials for passive components in EV-based power electronics converters at the system level are considered as benefits and trends of adopting WBG. For the WBG progress, commercial $\mathrm{SiC}$ devices with higher voltages and currents up to $3.3 \mathrm{kV} / 800 \mathrm{~A}$, and the $\mathrm{F}_{\mathrm{sw}}$ up to several hundreds' $\mathrm{kHz}$ are more acceptable to be used in EV-based motor drive. GaN devices with voltages and currents up to $900 \mathrm{~V} / 150 \mathrm{~A}$ and $\mathrm{F}_{\text {sw }}$ up to $\mathrm{MHz}$ range are more suitable to be employed for the onboard DC/DC converter and charger to meet the needs of higher efficiency, power density, with reduced size and volume in Figure 3.

For WBG challenges, designers still need to know comprehensive characteristics of WBG devices, where power losses of GaN-based power converter in EV systems are unpredictable due to current collapse. Therefore, overengineering is unavoidable. Minimizing $\mathrm{L}_{\text {para }}$ to nano or even pico-Henry range is important to reduce overshoot, sustained oscillations of WBG power converters. Minimizing the EMI noise level but retaining the benefits of WBG fast switching also brings to designers' challenges. The effective packaging of the WBG power module to decrease $L_{\text {para }}$ and $R_{\text {th }}$ is another important challenge to apply for hybrid EV-based power electronics converters. To tackle the challenges, different solutions are reviewed, which gives designers many directions. 


\section{References}

[1] T. V Do, K. Li, J. P. Trovão, and L. Boulon, "Reviewing of Using Wide-bandgap Power Semiconductor Devices in Electric Vehicle Systems : from Component to System," 2020 IEEE Veh. Power Propuls. Conf. (VPPC), Gijon, Spain, pp. 1-6, 2020, doi: 10.1109/VPPC49601.2020.9330854.

[2] K. Li, P. Evans, and M. Johnson, "SiC/GaN power semiconductor devices: A theoretical comparison and experimental evaluation under different switching conditions," IET Electr. Syst. Transp., vol. 8, no. 1, pp. 3-11, 2018, doi: 10.1049/iet-est.2017.0022.

[3] T. Bertelshofer, R. Horff, A. Marz, and M. M. Bakran, "Comparing $650 \mathrm{~V}$ and $900 \mathrm{~V} \mathrm{SiC} \mathrm{MOSFETs} \mathrm{for} \mathrm{the}$ application in an automotive inverter," 2016 18th Eur. Conf. Power Electron. Appl. EPE 2016 ECCE Eur., 2016, doi: 10.1109/EPE.2016.7695540.

[4] K. Li, A. Videt, N. Idir, P. Evans, and M. Johnson, "Experimental investigation of gan transistor current collapse on power converter efficiency for electrical vehicles," 2019 IEEE Veh. Power Propuls. Conf. VPPC 2019 - Proc., pp. 1924, 2019, doi: 10.1109/VPPC46532.2019.8952479.

[5] A. B. Jorgensen, S. Beczkowski, C. Uhrenfeldt, N. H. Petersen, S. Jorgensen, and S. Munk-Nielsen, "A FastSwitching Integrated Full-Bridge Power Module Based on GaN eHEMT Devices," IEEE Trans. Power Electron., vol. 34, no. 3, pp. 2494-2504, 2019, doi: 10.1109/TPEL.2018.2845538.

[6] K. Numakura, K. Emori, Y. Yoshino, Y. Hayami, and T. Hayashi, "Direct-cooled power module with a thick $\mathrm{Cu}$ heat spreader featuring a stress-suppressed structure for EV/HEV inverters," ECCE 2016 - IEEE Energy Convers. Congr. Expo. Proc., 2016, doi: 10.1109/ECCE.2016.7855049.

[7] T. Hirao, M. Onishi, Y. Yasuda, A. Namba, and K. Nakatsu, "EV Traction Inverter Employing Double-Sided DirectCooling Technology with SiC Power Device," 2018 Int. Power Electron. Conf. IPEC-Niigata - ECCE Asia 2018, vol. 3, no. c, pp. 2082-2085, 2018, doi: 10.23919/IPEC.2018.8507756.

[8] Z. Gu et al., "Comparison of wide-bandgap devices in $1 \mathrm{kV}$, 3 kW LLC converters," Chinese J. Electr. Eng., vol. 6, no. 3, pp. 65-72, 2020, doi: 10.23919/CJEE.2020.000020.

[9] A. Bhalla et al., "Ultra-high speed $7 \mathrm{mohm}, 650 \mathrm{~V} \mathrm{SiC}$ halfbridge module with robust short circuit capability for EV inverters," Proc. Int. Symp. Power Semicond. Devices ICs, vol. 2019-May, pp. 191-194, 2019, doi: 10.1109/ISPSD.2019.8757666.

[10] J. Dai, J. Li, P. Agyakwa, M. Corfield, and C. M. Johnson, "Comparative thermal and structural characterization of sintered nano-silver and high-lead solder die attachments during power cycling," IEEE Trans. Device Mater. Reliab., vol. 18, no. 2, pp. 256-265, 2018, doi: 10.1109/TDMR.2018.2825386.

[11] Z. Bai et al., "Investigation on Single Pulse Avalanche Failure of $1200-\mathrm{V}$ SiC MOSFETs via Optimized Thermoelectric Simulation," IEEE Trans. Electron Devices, vol. 68, no. 3, pp. 1168-1175, 2021, doi: 10.1109/TED.2020.3048921.

[12] F. Principato, S. Altieri, L. Abbene, and F. Pintacuda, "Accelerated tests on $\mathrm{Si}$ and $\mathrm{SiC}$ power transistors with thermal, fastand ultra-fast neutrons," Sensors (Switzerland), vol. 20, no. 11, pp. 1-15, 2020, doi: 10.3390/s20113021.

[13] H. Kim, H. Chen, J. Zhu, D. Maksimovic, and R. Erickson, "Impact of $1.2 \mathrm{kV} \mathrm{SiC-MOSFET} \mathrm{EV} \mathrm{traction} \mathrm{inverter} \mathrm{on}$ urban driving," WiPDA 2016 - 4th IEEE Work. Wide Bandgap Power Devices Appl., pp. 78-83, 2016, doi: 10.1109/WiPDA.2016.7799913.

[14] W. W. and D. X. Y. Guan, Y. Wang, "Analysis and Design of a 1-MHz Single-Switch DC-DC Converter With Small
Winding Resistance," vol. 65, no. 10, pp. 7805-7817, 2018.

[15] C. Fei, F. C. Lee, and Q. Li, "High-Efficiency High-PowerDensity LLC Converter with an Integrated Planar Matrix Transformer for High-Output Current Applications," IEEE Trans. Ind. Electron., vol. 64, no. 11, pp. 9072-9082, 2017, doi: 10.1109/TIE.2017.2674599.

[16] Y. Mao, Z. Miao, C. M. Wang, and K. D. T. Ngo, "Balancing of Peak Currents between Paralleled SiC MOSFETs by Drive-Source Resistors and Coupled Power-Source Inductors," IEEE Trans. Ind. Electron., vol. 64, no. 10, pp. 8334-8343, 2017, doi: 10.1109/TIE.2017.2716868.

\section{Acknowledgements}

This work is supported in part by Grant 950-230672 from Canada Research Chairs Program and in part by Grants RGPIN-2017-05924 and CRDPJ 497994-16 from the Natural Sciences and Engineering Research Council of Canada.

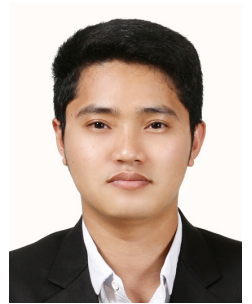

Thang Van Do (Thang.Do.Van.Thang@USherbrooke.ca) received his B.S. degree from $\mathrm{Ha}$ Noi University of Science and Technology, Ha Noi, Viet Nam, in 2017, in control and automation engineering, the M.S. degree in electrical engineering from Changwon National University, Changwon, South Korea, in 2019. He is currently pursuing the Ph.D. degree in electrical engineering with University of Sherbrooke, Sherbrooke, Canada. His research interests include power electronics, renewable energy, and electric vehicles.

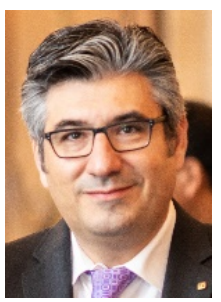

João $\quad$ Pedro $\quad$ F. $\quad$ Trovão (Joao.Trovão@USherbrooke.ca) (SM'17) the Ph.D. degree in Electrical Engineering from the University of Coimbra, Coimbra, Portugal, in 2013. Since 2014, he has been a Professor with the Department of Electrical Engineering and Computer Engineering, University of Sherbrooke, Sherbrooke, QC, Canada, where he holds the Canadian Research Chair position in Efficient Electric Vehicles with Hybridized Energy Storage Systems. He is an author/coauthor of over 130 journal and conference papers. His research interests cover the areas of electric vehicles, hybridized energy storage systems, energy management and rotating electrical machines.

Dr. Trovão was the General Chair of the 2018 IEEE Vehicle Power and Propulsion Conference, Chicago, US. He was a Guest Editor for the Special Issue of IET ElECtrical Systems in Transportation ON ENERgy StORAge and Electric POWER Sub-Systems FOR AdVANCED Vehicles. He was a Guest Editor for the Special Issues of IEEE TRANSACTIONS ON Vehicular TeChNOlogy ON Electric POWERTRains FOR Future Vehicles AND ON AdVANCED Vehicle Power Propulsion Systems. He is a founding member and the director of the electric-Transport, Energy Storage and Conversion (e-TESC) Lab of the University of Sherbrooke. He is a Senior Editor for the Automotive Electronics topic of the IEEE Vehicular TeChNology Magazine. 


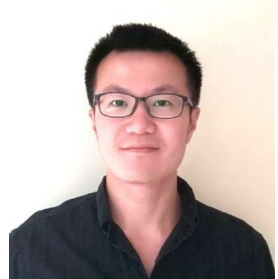
interests include wide-bandgap $(\mathrm{SiC} / \mathrm{GaN})$ power

Ke LI (ke.li@coventry.ac.uk) (M'14) received the $\mathrm{Ph} . \mathrm{D}$ degree in electrical engineering from University of Lille, France, in 2014. From 2015 to 2019, he was Research Fellow at the University of Nottingham, UK. In 2019, he was appointed as Assistant Professor in power electronics, machines and drives, Coventry University, UK. His research semiconductor devices integration to high power-density power converters, power converters electrothermal and electromagnetic modelling and power converters electromagnetic interference mitigation.

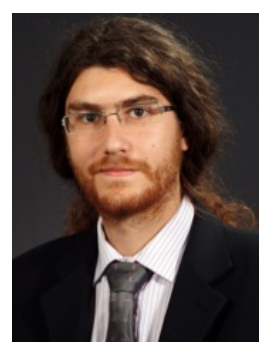

Loïc Boulon (Loic.Boulon@uqtr.ca) (SM'16) received the master's degree in electrical and automatic control engineering from the University of Lille (France), in 2006. Then, he obtained a $\mathrm{PhD}$ in electrical engineering from University of Franche-Comté (France). Since 2010, he is a professor at UQTR (Full Professor since 2016) and he works into the Hydrogen Research Institute (Deputy director since 2019).

His work deals with modeling, control, and energy management of multiphysics systems. His research interests include hybrid electric vehicles, energy, and power sources (fuel cell systems, batteries and ultracapacitors). He has published more than 140 scientific papers in peer-reviewed international journals and international conferences and given over 40 invited conferences all over the word. In 2019, he is the world most cited authors of the topic "Proton exchange membrane fuel cells (PEMFC); Fuel cells; Cell stack" in Elsevier SciVal.

In 2015, Loïc Boulon was general chair of the IEEE-Vehicular Power and Propulsion Conference in Montréal (QC, Canada). Prof. Loïc Boulon is now VP-Motor Vehicles of the IEEE Vehicular Technology Society and he found the "IEEE VTS Motor Vehicle Challenge". He is the holder of the Canada Research Chair in Energy Sources for the Vehicles of the future and the Director of the Réseau Québécois sur l'Energie Intelligente. 